OPEN ACCESS

Edited by:

Kevin G. Bath

Brown University, United States

Reviewed by:

Frauke Nees,

Central Institute for Mental Health,

Germany

Luciene Covolan

Federal University of São Paulo, Brazil

${ }^{*}$ Correspondence:

Ruth E. Grunau

rgrunau@bcchr.ca

Received: 14 December 2018 Accepted: 01 March 2019

Published: 19 March 2019

Citation:

Chau CMY, Ranger M, Bichin M.

Park MTM, Amaral RSC,

Chakravarty M, Poskitt K, Synnes AR,

Miller SP and Grunau RE (2019)

Hippocampus, Amygdala,

and Thalamus Volumes in Very

Preterm Children at 8 Years: Neonatal

Pain and Genetic Variation.

Front. Behav. Neurosci. 13:51.

doi: 10.3389/fnbeh.2019.00051

\section{Hippocampus, Amygdala, and Thalamus Volumes in Very Preterm Children at 8 Years: Neonatal Pain and Genetic Variation}

\author{
Cecil M. Y. Chau 1,2, Manon Ranger ${ }^{2,3}$, Mark Bichin ${ }^{1}$, Min Tae M. Park ${ }^{4,5}$, \\ Robert S. C. Amaral ${ }^{5}$, Mallar Chakravarty ${ }^{5}$, Kenneth Poskitt ${ }^{1,2}$, Anne R. Synnes ${ }^{1,2}$, \\ Steven P. Miller ${ }^{6}$ and Ruth E. Grunau ${ }^{1,2 *}$
}

\begin{abstract}
${ }^{1}$ Department of Pediatrics, The University of British Columbia, Vancouver, BC, Canada, ${ }^{2}$ BC Children's Hospital Research Institute, Vancouver, BC, Canada, ${ }^{3}$ School of Nursing, The University of British Columbia, Vancouver, BC, Canada, ${ }^{4}$ Department of Psychiatry, The University of Western Ontario, London, ON, Canada, ${ }^{5}$ Cerebral Imaging Centre, Douglas Mental Health University Institute, Montreal, QC, Canada, ${ }^{6}$ Department of Paediatrics, The Hospital for Sick Children, University of Toronto, Toronto, ON, Canada
\end{abstract}

Altered hippocampal morphology and reduced volumes have been found in children born preterm compared to full-term. Stress inhibits neurogenesis in the hippocampus, and neonatal stress/noxious stimulation in rodent pups are associated with longterm alterations in hippocampal volumes. We have previously shown reduced cortical thickness and cerebellar volumes in relation to more exposure to pain-related stress of neonatal invasive procedures in children born very preterm. We have reported targeted gene-by-pain environment interactions that contribute to long-term brain development and outcomes in this population. We now aim to determine whether exposure to pain-related stress (adjusted for clinical factors and genotype) differentially impacts regional structures within the limbic system and thalamus, and investigate relationships with outcomes in very preterm children. Our study included 57 children born very preterm ( $<32$ weeks GA) followed longitudinally from birth who underwent 3-D T1 MRI neuroimaging at $\sim 8$ years. Hippocampal subfields and white matter tracts, thalamus and amygdala were automatically segmented using the MAGeT Brain algorithm. The relationship between those subcortical brain volumes (adjusted for total brain volume) and neonatal invasive procedures, gestational age (GA), illness severity, postnatal infection, days of mechanical ventilation, number of surgeries, morphine exposure, and genotype (COMT, SLC6A4, and BDNF) was examined using constrained principal component analysis. We found that neonatal clinical factors and genotypes accounted for $46 \%$ of the overall variance in volumes of hippocampal subregions, tracts, basal ganglia, thalamus and amygdala. After controlling for clinical risk factors and total brain volume, greater neonatal invasive procedures was associated with lower volumes in the amygdala and thalamus $(p=0.0001)$ and an interaction with COMT genotype predicted smaller hippocampal subregional volume $(p=0.0001)$. More surgeries, days 
of ventilation, and lower GA were also related to smaller volumes in various subcortical regions $(p<0.002)$. These reduced volumes were in turn differentially related to poorer cognitive, visual-motor and behavioral outcomes. Our findings highlight the complexity that interplays when examining how exposure to early-life stress may impact brain development both at the structural and functional level, and provide new insight on possible novel avenues of research to discover brain-protective treatments to improve the care of children born preterm.

Keywords: preterm, pain, stress, hippocampus, amygdala, thalamus, limbic, genes

\section{INTRODUCTION}

Children born very preterm [24-32 weeks gestational age (GA)] are at risk for cognitive, emotional and behavior problems, persisting to adulthood (e.g., Anderson et al., 2003; Grunau et al., 2004; Doyle and Anderson, 2010; Linsell et al., 2018). Very preterm infants are exposed to developmentally unexpected environmental stress in the neonatal intensive care unit (NICU) during a critical period of rapid brain development and programming of stress systems. These infants undergo about 10 noxious procedures per day (Simons et al., 2003; Carbajal et al., 2008; Johnston et al., 2011; Roofthooft et al., 2014). In infants born very preterm, we have previously reported that greater exposure to neonatal pain-related stress is associated with altered brain microstructure (Brummelte et al., 2012; Ranger et al., 2013, 2015; Zwicker et al., 2013; Vinall et al., 2014) and processing (Doesburg et al., 2013), as well as programming of the hypothalamic-pituitary-adrenal (HPA) axis indexed by cortisol levels (Grunau et al., 2013; Brummelte et al., 2015), cognitive function (Grunau et al., 2009), and anxiety/depressive behaviors (Ranger et al., 2014).

Changes in maturation of the limbic system (Kinney, 2009) and basal ganglia (Peterson et al., 2000; Brunnemann et al., 2013; Scheinost et al., 2016) have been reported in children born preterm, associated with poorer behavioral (Rogers et al., 2017) and cognitive outcomes (Ball et al., 2015). Subcortical brain structures including hippocampus, amygdala, thalamus, and basal ganglia comprise the limbic system, involved in emotion, learning, and memory. Moreover, the thalamus is a relay center, directing sensory information from the periphery to other brain regions for processing, including the cerebral cortex. We recently found in infants born very preterm that thalamic volume, metabolism and structural maturation, were related to greater exposure to neonatal pain-related stress (Duerden et al., 2018; Schneider et al., 2018), and in turn, associated with poorer cognitive and motor outcomes (Duerden et al., 2018). However, the relationship between neonatal pain/stress exposure and the structures adjacent to thalamus, including the limbic system and basal ganglia, have not been examined.

There is wide variation in long-term outcomes of children born very preterm, even among those of similar gestational age, exposure to neonatal pain/stress and other clinical factors. Genetic vulnerability to early adversity has been identified, for example catechol-O-transferase (COMT) for pain sensitivity (Diatchenko et al., 2005; Hoth et al., 2006; Nackley et al., 2006), serotonin transporter [SLC6A4] in stress regulation (Lucki, 1998; Lesch, 2007) and brain-derived neurotrophic factor $(B D N F)$ for brain synaptic plasticity (Gerritsen et al., 2012; Lakshminarasimhan and Chattarji, 2012; Kim et al., 2013). The Catechol-O-methyltransferase (COMT) gene encodes a key enzyme in the degradation of catecholamines (serotonin, dopamine, norepinephrine) (Lotta et al., 1995). COMT Val158Met is a common haplotype of the human COMT gene. The Met/Met genotype of the COMT Val158Met variant is associated with more than a three- to fourfold decrease in COMT enzyme activity and dopamine (DA) catabolism, which leads to an increase in DA availability in the prefrontal cortex (PFC) (Lotta et al., 1995; Chen et al., 2004). COMT Val158 leads to lower synaptic dopamine levels and poorer prefrontal functions with increased risk of mood disorders. On the other hand, the Met158 allele has been linked to greater pain sensitivity (Diatchenko et al., 2005; Nackley et al., 2006), and anxiety (Olsson et al., 2007).

Serotonin (5-HT) receptors are widely distributed in the brain, including regions regulating emotion, attention, cognition, and learning (Lucki, 1998; Lesch, 2007). Allelic variations in the serotonin transporter promoter region (5HTTLPR) influence gene transcription and serotonin transporter (SLC6A4) levels, and therefore have a critical role in determining intrasynaptic 5-HT levels. Alterations in 5-HT neurotransmission have been associated with reduced gray matter in areas of the limbic system (Pezawas et al., 2005). Finally, brain-derived neurotrophic factor (BDNF), an important neurotrophin widely expressed in the brain, especially in hippocampal regions, affects long-term neuronal survival, development and synaptic plasticity. Human postmortem (Chen et al., 2001) and animal studies have found that stress exposure modifies BDNF expression: decreased expression in hippocampus and increased in amygdala (Rasmusson et al., 2002; Govindarajan et al., 2006; Lakshminarasimhan and Chattarji, 2012). The BDNF Val66Met (rs6265) variant affects intracellular processing and secretion of BDNF (Egan et al., 2001). The Met allele encodes a precursor protein with impaired function which results in lower BDNF availability, and hence is associated with alterations of human hippocampal function and episodic memory (Egan et al., 2003).

In a targeted approach, we previously found gene polymorphisms associated with increased vulnerability to 
pain/stress exposure in very preterm neonates. We examined gene by environment interactions between neonatal pain/stress and genetic variations related to dopaminergic and serotonergic pathways, and also examined epigenetic changes in methylation in the promotor region of SLC6A4 (Chau et al., 2014). We found that neonatal pain/stress exposure interacted with the COMT genotype to predict the level of SLC6A4 methylation at age 7 years in children born very preterm, which in turn was associated with behavior. A group in Italy also reported similar findings, that exposure to neonatal pain/stress was associated with DNA methylation of SLC6A4 in very preterm infants at term-equivalent age (Provenzi et al., 2015). Taken together, these studies suggest that long-term alterations in gene expression in infants born very preterm are at least partially induced by exposure to pain/stress of invasive procedures in the NICU. Moreover, we recently reported that the BDNF genotype moderated the association between neonatal pain/stress and cortisol (levels and reactivity) at age 7 years in boys, but not girls, born very preterm. Cortisol reactivity was associated with cognitive function and visual-motor integration in these children (Chau et al., 2017).

In the present study, we examined in school-age children born very preterm whether the extent of exposure to procedural pain/stress in the NICU, acting directly and/or through genetic interaction with COMT, BDNF, 5HTTLPR, is associated with development of subcortical structures in the limbic system (hippocampal network, amygdala and thalamus) and the basal ganglia (striatum, and globus pallidus), after accounting for clinical factors associated with prematurity. We hypothesize that: (1) neonatal pain/stress will be related to subregional volumes in the limbic system and basal ganglia; (2) genotypes will moderate the relationship between pain/stress and subcortical volumes; (3) relationships between pain/stress, genotypes, and outcomes will vary by subcortical region (e.g., hippocampus for working memory, amygdala for depressive/anxiety symptoms, and thalamus for visual motor integration). The findings of this study may inform possible pathways and vulnerability for pain-related stress to affect outcomes in children born very preterm.

\section{MATERIALS AND METHODS}

\section{Study Design and Participants}

Participants were part of a larger longitudinal study of longterm effects of neonatal pain-related stress on neurodevelopment of children born very preterm (24-32 weeks gestation), e.g., (Grunau et al., 2007, 2009) admitted to the level III NICU at British Columbia's Women's Hospital between 2000 and 2004. Of 106 very preterm children seen at 8 years, 61 underwent MRI. Of these 61 children, two with periventricular leukomalacia (PVL) and/or intraventricular hemorrhage (IVH) grade 3 or 4 on neonatal ultrasound, confirmed on MR scans at 8 years, were excluded. Three children with ventriculomegaly and six who showed minimal to moderate white matter injury ( $\leq 3$ lesions) on MR scans at school age were included in the study, since none of them were outliers on total brain and hippocampal volumes compared to the rest of the sample. An additional two children were excluded due to excessive movement artifact, therefore a total of 57 children ( $45 \%$ boys) comprised the study sample. All children in the final sample of 57 had a full scale IQ above 72 on the Wechsler Intelligence Scale for Children 4th Ed (WISC-IV) (Wechsler, 2003), and none had a major sensory or motor impairment.

The study was approved by the Clinical Research Ethics Board of the University of British Columbia and the British Columbia Children's and Women's Research Ethics Board. Written informed consent was obtained from parents and assent from children.

\section{Procedures \\ Clinical Data Collection}

Medical and nursing chart review of neonatal data from birth to term equivalent was carried out by highly trained neonatal research nurses. Data collected included, but was not limited to, birth weight, gestational age (GA), small for gestational age (SGA; birth weight $<10 \%$ tile), number of days on mechanical ventilation and/or oscillation, illness severity on day 1 [Score for Neonatal Acute Physiology (SNAP)- II (Richardson et al., 2001)], number of surgeries, presence of culture proven infection, and cumulative dose of morphine. The cumulative dose of morphine was calculated (intravenous dose plus converted oral dose) as the average daily dose adjusted for daily body weight, multiplied by the number of days the drug was given, as we have used previously (Grunau et al., 2009; Brummelte et al., 2012). We quantified exposure to neonatal invasive procedures as the number of skin-breaking procedures (e.g., heel lance, peripheral intravenous or central line insertion, chest-tube insertion, tape removal, and nasogastric tube insertion) during the stay in the NICU, as previously used (Grunau et al., 2005, 2009; Brummelte et al., 2012). Each attempt at a procedure was counted as one skinbreak; all nursing staff in our NICU have been trained to precisely record each attempt.

\section{Magnetic Resonance Imaging}

The MRI was performed using a standard 12 channel head coil on a Siemens 1.5 Tesla Avanto (Berlin, Germany) with VB 16 software. The following images were acquired: a 3D T1 weighted SPGR sequence 18/9.2/256/1 mm/0/256 × 256 (TR/TE/FOV/Thickness/Gap/Matrix), axial FSE T2 4030/90/ $220 / 3 \mathrm{~mm} / 0.1 \mathrm{~mm} / 512 \times 354$, axial FLAIR $8900 / 87 / 5 \mathrm{~mm} / 1 \mathrm{~mm} /$ $256 \times 154$ and a 12 direction DTI sequence 7800/82/256/2 mm/ $0 / 128 \times 128$ using B values of 700 and 1000 . All imaging sessions were performed without sedation. On the study day, each child first had a session in a mock scanner to acclimatize to the noise and feeling of undergoing MRI, followed by the actual study scan. Children were instructed to remain still and watched a video during the sessions that lasted approximately $30 \mathrm{~min}$.

An experienced pediatric neuroradiologist (KP), blinded to the child's medical history, assessed the MR scans for ventriculomegaly, cerebellar hemorrhage and severity of white matter injury, as previously described (Vinall et al., 2013). No child had a severe brain injury at school age [i.e., no cerebellar 
hemorrhage or severe white matter injury (i.e., $>3$ lesions or 2 with $5 \%$ hemisphere involved)].

\section{MR Image Segmentation and Analysis}

An automatic segmentation protocol based on the MAGeT Brain (Multiple Automatically Generated Templates) algorithm (Pipitone et al., 2014) was used to delineate the following: hippocampal subfields [cornus ammonis (CA) 1, subiculum, CA4/dentate gyrus (DG), CA2/CA3, stratum radiatum/lacunosum/molecular] (Winterburn et al., 2013), hippocampal white matter (alveus, fimbria, fornix, and mammillary bodies) (Amaral et al., 2018), basal ganglia (striatum and globus pallidus) and thalamus (Chakravarty et al., 2013) of preterm children (Guo et al., 2015). Total of 26 bilateral regions (13 regions in each hemisphere) were segmented and included in this study. All automated segmentations were visually inspected by an expert rater before inclusion (MP; RA).

\section{Genotyping}

Genomic DNA was extracted from neonatal whole blood samples using the Flexigene DNA Blood Kit (Qiagen, Valencia, California). The COMT Val158Met (rs4680) variant and BDNF Val66Met (rs6265) were genotyped using TaqMan SNP Genotyping Assay reagents and an Applied Biosystems 7300 Real Time PCR System (Applied Biosystems, Carlsbad, CA, United States). Call rate was $100 \%$. Due to the low frequencies of the BDNF Met allele, subjects with the Met/Met and the Val/Met genotypes were grouped together in all analyses. The Hardy-Weinberg equilibrium of allelic distribution of the cohort was examined and compared to the population distribution by chi-square test.

The S and L alleles of SLC6A4 HTTLPR were identified as previously described in Lesch et al. (1996). Polymerase chain reaction was performed with oligonucleotide primers flanking the polymorphism (corresponding to nucleotide positions -1416 to -1397 [stpr5, 5_-GGCGTTGC CGCTCTGAATGC] and -910 to -888 [stpr3, 5_-GAGG GACTGAGCTGGACAACCAC]) of the 5_-flanking regulatory region of SLC6A4 to generate a 484-bp (S short allele) or a 528-bp (L long allele) polymerase chain reaction product. Polymerase chain reaction amplification was performed in a final volume of $30 \mu \mathrm{L}$ with $50 \mathrm{ng}$ of genomic DNA, $2.5 \mathrm{mM}$ deoxyribonucleotides (dGTP/7-deaza-2_-dGTP $=1 / 1), 0.1 \mu \mathrm{g}$ of sense and antisense primers, $10 \mathrm{mM}$ Tris hydrochloride $(\mathrm{pH}$ 8.3), $50 \mathrm{mM}$ potassium chloride, $1.5 \mathrm{mM}$ magnesium chloride, and $1 \mathrm{U}$ of Taq DNA polymerase. For quality control, $5 \%$ of the samples were randomly chosen to be retested and their genotypes were consistent with previous results.

\section{Cognitive, Motor and Behavioral Outcomes Measures} Children's cognitive performance was assessed by Wechsler Intelligence Scale for Children 4th Ed (WISC-IV) composite scores [Verbal Comprehension Index (VCI), Perceptual Reasoning Index (PRI), Working Memory (WMI), Processing Speed Index (PSI)] (Wechsler, 2003).
Parents rated their child's behavior using the Child Behavioral Check List (CBCL) for children ages 6-18 years (Achenbach and Rescorla, 2000). The internalizing and externalizing subscales $T$-scores were used as the indicator of child behavior in the current study. The internalizing scale encompasses anxious/depressed, withdrawn/depressed, somatic problems, whereas the externalizing scale includes aggressive and rulebreaking behaviors. Behavior Rating Inventory of Executive Function (BRIEF) Global Executive Composite (GEC) score was used to assess executive function behavior (Gioia et al., 2000). The Beery Developmental Test of Visual-Motor Integration (VMI) was used to measure visual-motor coordination (Beery and Beery, 2004); the Beery Motor Coordination and Visual Perception subscales were of particular interest for this study.

\section{Statistical Analysis}

Constrained principal component analysis (CPCA) with interaction terms was used to examine the effects of seven neonatal clinical variables of interest (GA, neonatal infection, number of invasive procedures, number of surgeries, days on mechanical ventilation, illness severity on day 1 , morphine exposure), BDNF, SLC6A4, and COMT genotypes, on the volumes of hippocampal subregions, hippocampus-related tracts, basal ganglia, thalamus and amygdala.

Constrained principal component analysis is a 2 -step process, referred to as the external and internal analysis. First, the external analysis consists of a multivariate least squares multiple regression of the dependent measures on the independent measures, producing predicted and residual scores for each dependent measure. In the present study, the matrix of predicted scores reflect the variation in volume of hippocampus subregions and white matter tracts, amygdala, basal ganglia, and thalamus, in relation to the seven neonatal clinical variables, total brain volume and three genotypes, then by the interactions between clinical variables and genotypes. The major allele for each gene (e.g., BDNF Val66Met Val/Val) was the reference category in all analyses that included genotypes.

The second step, the internal analysis, comprised principal component analyses on each of the aforementioned matrices, including main effects and interaction terms. The resulting component solutions (overall, predicted, and residual solutions) were examined to determine which subregional volumes of the limbic system and basal ganglia could be explained by the neonatal clinical variables, genotypes, and interaction term. CPCA results were bootstrapped 1,000 times to compute confident intervals and $p$-values. Multiple comparison were adjusted by $5 \%$ Benjamini-Hochberg False discovery rate (FDR) (Benjamini and Hochberg, 1995) and Bonferroni method. Details of CPCA have been described previously (Ranger et al., 2013, 2015). Computations for CPCA were done using MATLAB v 8.5.0 (R2015a) (The MathWorks, 2010, Natick, MA, United States).

Given our interest in the functions supported by the subcortical structures comprising the limbic system and basal ganglia (e.g., memory and behavior), CPCA component loadings were examined for associations with WISC IV composite scores (VCI, PRI, WMI, and PSI), CBCL T-scores (Internalizing and 
Externalizing), BRIEF GEC scores, as well as the Beery VMI, Visual Perception and Motor coordination scores.

\section{RESULTS}

\section{Neonatal Clinical Factors Predict Limbic and Basal Ganglia Volumes at 8 Years}

Participant characteristics are presented in Table 1. Genotype distribution is summarized in Table 2. The allelic distribution of our sample did not differ from the Hardy-Weinberg Equilibrium from the population.

The external analysis of CPCA showed that the predictor variables (7 neonatal clinical factors, total brain volumes, and BDNF, SLC6A4, COMT genotypes) accounted for $46.1 \%$ of the overall variance in volumes of hippocampal subregions, tracts, basal ganglia, thalamus and amygdala (Table 3 ). Two main components (PC1 and PC2) were extracted from the predicted

TABLE 1 | Participant characteristics.

\begin{tabular}{|c|c|}
\hline Neonatal & $N=57$ (26 boys, 31 girls) \\
\hline Gestational age at birth (GA, wks) & $29.7(27.6-31.7)$ \\
\hline Birth weight (g) & $1285(920-1560)$ \\
\hline Small for gestational age $(n, \%)$ & $6(11)$ \\
\hline IIness severity day 1 (SNAP-II) & $8(0-18.5)$ \\
\hline Pain/stress (\# invasive procedures) & $74(46.5-131)$ \\
\hline Infants mechanically ventilated ( $n, \%)$ & $35(61.4)$ \\
\hline Days of mechanical ventilation & $9(0-71)$ \\
\hline Culture proven infection ( $n, \%)$ & $14(24.6)$ \\
\hline Surgery $(n, \%)$ & $11(19.3)$ \\
\hline Morphine exposure $\left(\mathrm{mg} / \mathrm{kg}^{\prime}\right)$ & $0.03(0-0.7)$ \\
\hline Postnatal corticosteroid exposure ( $n$, days) & $6(2-24)$ \\
\hline Child & Mean (range) \\
\hline Age at scan (years) & $7.9(7.7-8)$ \\
\hline Total brain volume $\left(\mathrm{cm}^{3}\right)$ & $1397.0(1123.4-1759.0)$ \\
\hline Total right/left hippocampal volume $\left(\mathrm{cm}^{3}\right)$ & $214(199-234) / 221(201-236)$ \\
\hline Total right/left amygdala volume & $111(108-123) / 117(109-125)$ \\
\hline Total right/left thalamus volume & $623(582-668) / 588$ (551-629) \\
\hline WISC-IV Full Scale IQ & $101(73-135)$ \\
\hline WISC-IV VCI & $100(77-136)$ \\
\hline WISC-IV PRI & $104(69-147)$ \\
\hline WISC-IV WMI & $99(77-120)$ \\
\hline WISC-IV PSI & $98(75-131)$ \\
\hline CBCL Internalizing Problems & $53(34-80)$ \\
\hline CBCL Externalizing Problems & $48(33-77)$ \\
\hline BRIEF GEC & $53(35-86)$ \\
\hline Beery Visual Motor Integration & $94(75-112)$ \\
\hline Beery Visual Perception & $105(77-143)$ \\
\hline Beery Motor Coordination & $92(60-113)$ \\
\hline
\end{tabular}

WISC-IV, Wechsler Intelligence Scale for Children 4th Ed; VCl, Verbal Comprehension Index; PRI, Perceptual Reasoning Index; WMI, Working Memory Index; PSI, Processing Speed Index; CBCL, Child Behavior Checklist; BRIEF, Behavior Rating Inventory of Executive Function; GEC, Global Executive Composite; Beery VMI, Beery Visual Motor Integration. Values are means and ranges, unless otherwise specified. 'Cumulative daily dose adjusted for daily body weight multiplied by the number of days drug received.
TABLE 2 | Genotypes distribution.

\begin{tabular}{llcc}
\hline Genes & Genotypes & $\mathbf{N}=\mathbf{5 7}$ & HWE $\boldsymbol{p}$-value $^{\mathbf{a}}$ \\
\hline BDNF Val66Met rs6265 & Val/Nal & 38 & 0.655 \\
& Val/Met + Met/Met & 19 & \\
SLC6A4 5HTTLPR & L/L & 14 & 0.802 \\
& L/S + S/S & 43 & \\
COMT Val158Met rs4680 & Val/Nal & 17 & 0.956 \\
& Val/Met & 27 & \\
& Met/Met & 12 & \\
\hline
\end{tabular}

${ }^{a} p$-values of independent 2-tailed t-test comparing Hardy-Weinberg Equilibrium (HWE) and study sample allelic distributions.

solutions comprising neonatal clinical factors (NCF) and genotypes $(\mathrm{G})$ independently, which corresponded, respectively, to 26.0 and $20.1 \%$ of the overall variance. Another component (PC NCFxG) reflected the interactions between the neonatal clinical factors and genotypes $(\mathrm{NCF} \times \mathrm{G})$. All these extracted components (PC1, PC2, and PC NCFxG) were orthogonal (i.e., did not correlate with each other).

Component loadings, their bootstrapped $p$-values and FDR adjusted $p$-values for each hippocampal subregions, tracts, thalamus and amygdala volumes predicted by NCF, $G$ independently and NCFxG interaction are summarized in Table 4. For the volumes explained by NCF and G independently, both components PC1 and PC2 negatively loaded on all hippocampal subregions, tracts, amygdala and thalamus volumes (i.e., indicating smaller volumes). The dominant loadings on the first component (PC1) were distributed bilaterally (on right and left hemispheres) on most of the subregions, but prominently (greater loadings) on amygdala and thalamus. For the second component (PC2), hippocampal subregions had the largest loadings. For the volumes explained by the NCFxG interaction, all subregions significantly explained by component PC NCFxG were negatively loaded and the dominant loadings were distributed mainly on the right hemisphere's hippocampal subregions and related tracts.

Component 1 (PC1) and 2 (PC2) were negatively related to regional volumes of the limbic system (see Table 4). We then examined how each neonatal variable loaded on the components (Table 5). To understand the relationships between neonatal factors and regional brain volumes, Tables 4 and 5 need to be considered together. As expected, total brain volume was negatively loaded on both components (Table 5), indicating that bigger total brain volume was associated with larger volume of subregions (Table 4). Component 1 (PC1) reflecting more neonatal invasive procedures and more days of ventilation (Table 5), was related to smaller volumes particularly in amygdala and thalamus (Table 4); lower GA (Table 5) was associated with smaller volumes as well (Table 4). Component 2 (PC2) represented total number of surgeries (Table 5), where greater number of surgeries was associated with smaller volumes, particularly in the hippocampal subregions (Table 4). None of the genotypes significantly loaded on either components, indicating that on their own, genotypes were not associated with hippocampal subregions, tracts, amygdala and thalamus volumes. 
TABLE 3 | Constrained principal component analysis (CPCA) results to explain variance in volumes of hippocampal subregions, tracts, basal ganglia, thalamus and amygdala in relation to neonatal clinical factors (NCF) and genotypes (G).

\begin{tabular}{|c|c|c|c|c|}
\hline CPCA clinical and genotype variables & Overall & PC1 & PC2 & $\mathrm{PC} 1+\mathrm{PC} 2$ \\
\hline Total variance & 26.46 & 9.45 & 8.19 & 17.64 \\
\hline$\%$ variance & 100.00 & 35.72 & 30.93 & 66.65 \\
\hline Variance explained by clinical variables and genotypes & 13.79 & 6.87 & 5.32 & 12.19 \\
\hline$\%$ variance explained by clinical variables and genotypes & 52.16 & 25.96 & 20.11 & 46.07 \\
\hline CPCA clinical x genotype interaction & & PC NCFX & & \\
\hline Variance explained by clinical variables $\mathbf{x}$ genotypes interaction & 4.72 & 1.34 & - & 1.34 \\
\hline$\%$ Variance explained by clinical variables $\mathbf{x}$ genotypes interaction & 17.84 & 5.08 & - & 5.08 \\
\hline
\end{tabular}

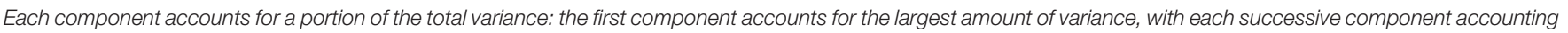

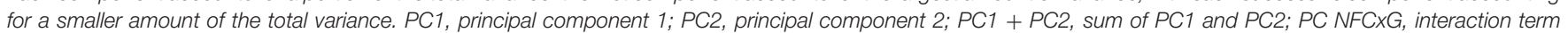
between neonatal clinical factors and genotypes.

TABLE 4 | CPCA component loadings predicted by neonatal clinical factors (NCF) and genotypes (G) independently and interactively.

\begin{tabular}{|c|c|c|c|c|c|c|c|c|c|}
\hline \multirow[b]{2}{*}{ Brain Regions } & \multicolumn{3}{|c|}{ PC1 } & \multicolumn{3}{|c|}{ PC2 } & \multicolumn{3}{|c|}{ PC NCFxG } \\
\hline & Loadings & $p$-value ${ }^{a}$ & FDR $^{b}$ & Loadings & $p$-value ${ }^{a}$ & FDR $^{b}$ & Loadings & $p$-value ${ }^{a}$ & FDR $^{b}$ \\
\hline L_CA1 & -0.259 & 0.093 & 0.105 & -0.950 & 0.0000 & 0.000 & -0.751 & 0.060 & 0.156 \\
\hline L_subiculum & -0.510 & 0.042 & 0.049 & -0.736 & 0.0120 & 0.017 & -0.130 & 0.758 & 0.984 \\
\hline L_CA4DG & -0.764 & 0.000 & 0.000 & -0.562 & 0.0004 & 0.001 & -0.738 & 0.018 & 0.058 \\
\hline L_CA2CA3 & -0.521 & 0.166 & 0.180 & -0.610 & 0.2175 & 0.226 & -0.556 & 0.052 & 0.150 \\
\hline L_stratum & -0.432 & 0.006 & 0.009 & -0.860 & 0.0000 & 0.000 & -0.815 & 0.009 & 0.036 \\
\hline R_CA1 & -0.427 & 0.005 & 0.009 & -0.859 & 0.0001 & 0.000 & -0.909 & 0.009 & 0.036 \\
\hline R_subiculum & -0.634 & 0.001 & 0.001 & -0.720 & 0.0004 & 0.001 & -0.254 & 0.476 & 0.858 \\
\hline R_CA4DG & -0.726 & 0.000 & 0.000 & -0.646 & 0.0002 & 0.000 & -0.802 & 0.000 & 0.003 \\
\hline R_CA2CA3 & -0.584 & 0.033 & 0.040 & -0.664 & 0.0283 & 0.037 & -0.607 & 0.009 & 0.036 \\
\hline R_stratum & -0.425 & 0.007 & 0.010 & -0.887 & 0.0000 & 0.000 & -0.829 & 0.010 & 0.036 \\
\hline L_Alveus & -0.570 & 0.012 & 0.016 & -0.739 & 0.0116 & 0.017 & -0.773 & 0.006 & 0.036 \\
\hline L_Fimbria & -0.850 & 0.000 & 0.000 & -0.361 & 0.1050 & 0.114 & -0.257 & 0.495 & 0.858 \\
\hline L_Fornix & -0.642 & 0.000 & 0.000 & -0.649 & 0.0001 & 0.000 & -0.029 & 0.970 & 0.984 \\
\hline L_Mam & -0.350 & 0.469 & 0.469 & -0.443 & 0.4073 & 0.407 & 0.282 & 0.384 & 0.832 \\
\hline R_Alveus & -0.552 & 0.026 & 0.034 & -0.663 & 0.0128 & 0.018 & -0.819 & 0.000 & 0.003 \\
\hline R_Fimbria & -0.800 & 0.000 & 0.000 & -0.475 & 0.0054 & 0.009 & -0.277 & 0.460 & 0.858 \\
\hline R_Fornix & -0.708 & 0.000 & 0.000 & -0.651 & 0.0000 & 0.000 & -0.457 & 0.379 & 0.832 \\
\hline R_Mam & -0.456 & 0.206 & 0.214 & -0.684 & 0.0590 & 0.067 & 0.181 & 0.588 & 0.899 \\
\hline L_amygdala & -0.761 & 0.000 & 0.000 & -0.611 & 0.0000 & 0.000 & -0.326 & 0.534 & 0.867 \\
\hline R_amygdala & -0.820 & 0.000 & 0.000 & -0.516 & 0.0001 & 0.000 & 0.217 & 0.718 & 0.982 \\
\hline L_striatum & -0.824 & 0.000 & 0.000 & -0.484 & 0.0005 & 0.001 & 0.217 & 0.817 & 0.984 \\
\hline L_gp & -0.895 & 0.000 & 0.000 & -0.363 & 0.0350 & 0.043 & 0.263 & 0.644 & 0.930 \\
\hline L_thalamus & -0.832 & 0.000 & 0.000 & -0.475 & 0.0034 & 0.006 & -0.036 & 0.953 & 0.984 \\
\hline R_striatum & -0.811 & 0.000 & 0.000 & -0.505 & 0.0003 & 0.001 & 0.123 & 0.890 & 0.984 \\
\hline R_gp & -0.905 & 0.000 & 0.000 & -0.357 & 0.0381 & 0.045 & 0.043 & 0.944 & 0.984 \\
\hline R_thalamus & -0.831 & 0.000 & 0.000 & -0.467 & 0.0061 & 0.010 & -0.011 & 0.984 & 0.984 \\
\hline
\end{tabular}

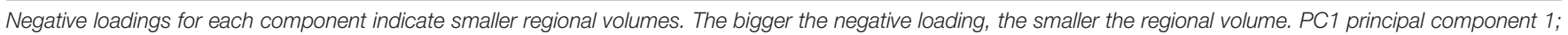

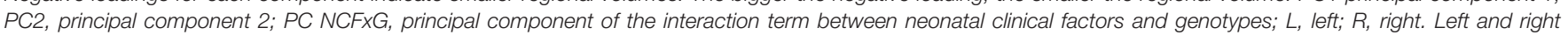

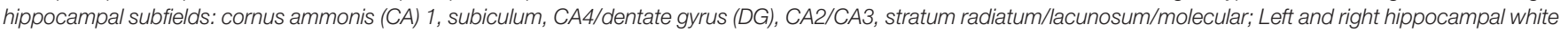

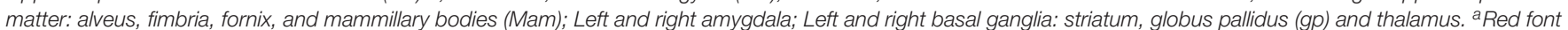

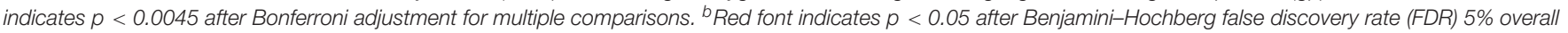
error rate adjustment.

\section{Gene by Environment Interaction to Predict Subcortical Volumes}

We further examined how the interaction between each of the seven neonatal clinical factors, total brain volume and each of the three genotypes loaded onto the interaction term (PC NCFxG) (Table 6). In our statistical model all minor alleles were coded as 1 and the major alleles were 0 , consequently negative loadings in the interaction terms represented smaller volumes with the 
TABLE 5 | Predictor loadings for neonatal clinical factors and genotypes.

\begin{tabular}{|c|c|c|c|c|c|c|}
\hline \multirow[b]{2}{*}{ Variables } & \multicolumn{3}{|c|}{ PC1 } & \multicolumn{3}{|c|}{ PC2 } \\
\hline & Loadings & $p$-value ${ }^{a}$ & FDR $^{\mathbf{b}}$ & Loadings & $p$-value ${ }^{a}$ & FDR $^{b}$ \\
\hline \multicolumn{7}{|l|}{$\begin{array}{l}\text { Neonatal clinical } \\
\text { factors }\end{array}$} \\
\hline Infection & 0.320 & 0.0126 & 0.023 & 0.105 & 0.4359 & 0.533 \\
\hline Invasive procedures & 0.483 & 0.0001 & 0.000 & -0.125 & 0.3465 & 0.533 \\
\hline Morphine & 0.238 & 0.0620 & 0.097 & 0.265 & 0.0532 & 0.146 \\
\hline Surgery & -0.085 & 0.5011 & 0.612 & 0.419 & 0.0019 & 0.010 \\
\hline $\begin{array}{l}\text { Mechanical } \\
\text { ventilation }\end{array}$ & 0.502 & 0.0001 & 0.000 & & 0.2663 & 0.488 \\
\hline SNAP-II Day 1 & 0.333 & 0.0111 & 0.023 & 0.274 & 0.0367 & 0.135 \\
\hline GA & -0.460 & 0.0005 & 0.001 & -0.106 & 0.4243 & 0.533 \\
\hline Total brain volume & -0.771 & 0.0000 & 0.000 & -0.513 & 0.0001 & 0.001 \\
\hline \multicolumn{7}{|l|}{ Genotypes } \\
\hline BDNF & -0.075 & 0.5743 & 0.632 & 0.051 & 0.7024 & 0.702 \\
\hline 5HTTLPR & 0.137 & 0.3232 & 0.444 & -0.229 & 0.0860 & 0.189 \\
\hline COMT & -0.051 & 0.7057 & 0.706 & -0.069 & 0.6166 & 0.678 \\
\hline \multicolumn{7}{|c|}{$\begin{array}{l}\text { Both PC1 and PC2 were negatively related to regional volumes of the limbic } \\
\text { system (Table 4). Significant positive loadings in this table indicate the relative } \\
\text { contribution of each clinical factor and genotype for each component. For example, } \\
\text { taking Tables } 4 \text { and } 5 \text { together, for PC1, more neonatal invasive procedures and } \\
\text { more days on mechanical ventilation were related to smaller regional volume of } \\
\text { CA4DG. PC1, principal component 1; PC2, principal component 2; Infection, } \\
\text { neonatal culture proven infection; Morphine, morphine exposure, Surgery, number } \\
\text { of surgeries; Ventilation, days on mechanical ventilation, SNAP-Il day 1, score for } \\
\text { neonatal acute physiology-II (i.e., illness severity on day 1); GA, gestation age. }{ }^{a} \text { Red } \\
\text { font indicate p }<0.0045 \text { after Bonferroni adjustment for multiple comparisons. } \\
{ }^{6} \text { Red font indicate } p<0.05 \text { after Benjamini Hochberg false discovery rate (FDR) } \\
5 \% \text { overall error rate adjustment. }\end{array}$} \\
\hline
\end{tabular}

minor alleles. Here we found that for very preterm children with the COMT 158Met/Met minor allele, greater neonatal invasive procedures exposure predicted smaller right hippocampal volumes $(p=0.0001)$; while greater GA was associated with larger right hippocampal volumes $(p=0.0001)$. For children with a BDNF 66Met major allele compared to those with BDNF 66ValVal genotype, presence of neonatal infection predicted larger right hippocampal subregional volumes $(p=0.0012)$. However, in those same children with a BDNF 66Met allele, greater number of surgeries was associated with smaller right hippocampal subregional volumes $(p=0.0002)$. Refer to Figure 1 for a comprehensive diagram of our CPCA model and findings.

It must be noted that some very preterm children included in this study were exposed to clinically relevant medications, such as dexamethasone $(n=5)$, hydrocortisone $(n=2)$, fentanyl $(n=8)$, and midazolam $(n=6)$, whose intake has been associated with decreased volumes in subcortical structures (Tam et al., 2011; Ranger et al., 2015; Duerden et al., 2016). However, due to the small sample size within each of these categories, we could not include these clinical factors as covariates in our model. To ensure that our findings were not driven by these factors, we reanalyzed the data using case wise deletion of the affected subjects; results remained consistent with our initial findings.
TABLE 6 | Predictor loadings for the interactions between each neonatal clinical factor $(\mathrm{NCF}) \times$ genotype $(\mathrm{G})$.

\begin{tabular}{|c|c|c|c|c|c|}
\hline \multirow{2}{*}{$\begin{array}{l}\text { NCF } \\
\text { Variables }\end{array}$} & & \multirow{2}{*}{$\begin{array}{l}\text { G } \\
\text { Variables }\end{array}$} & \multicolumn{3}{|c|}{ PC NCFxG } \\
\hline & & & Loadings & $p$-values ${ }^{a}$ & FDR $^{b}$ \\
\hline Infection & $x$ & BDNF & -0.419 & 0.0012 & 0.007 \\
\hline Infection & $\times$ & SLC6A4 & -0.261 & 0.0506 & 0.203 \\
\hline Infection & $\times$ & COMT & 0.253 & 0.0615 & 0.211 \\
\hline Inv.procedures & $\times$ & BDNF & -0.012 & 0.9279 & 0.928 \\
\hline Inv.procedures & $\times$ & SLC6A4 & 0.039 & 0.7734 & 0.844 \\
\hline Inv.procedures & $\times$ & COMT & 0.542 & 0.0001 & 0.001 \\
\hline Morphine & $\times$ & BDNF & 0.282 & 0.0360 & 0.173 \\
\hline Morphine & $\times$ & SLC6A4 & 0.196 & 0.1388 & 0.278 \\
\hline Morphine & $\times$ & COMT & 0.080 & 0.5504 & 0.695 \\
\hline Surgery & $\times$ & BDNF & 0.500 & 0.0002 & 0.001 \\
\hline Surgery & $\times$ & SLC6A4 & 0.230 & 0.0742 & 0.223 \\
\hline Surgery & $x$ & COMT & 0.089 & 0.4995 & 0.686 \\
\hline Ventilation & $\times$ & BDNF & 0.207 & 0.1272 & 0.278 \\
\hline Ventilation & $\times$ & SLC6A4 & 0.210 & 0.1170 & 0.278 \\
\hline Ventilation & $x$ & COMT & 0.203 & 0.1351 & 0.278 \\
\hline SNAP-II & $\times$ & BDNF & 0.122 & 0.3741 & 0.599 \\
\hline SNAP-II & $\times$ & SLC6A4 & 0.089 & 0.5143 & 0.686 \\
\hline SNAP-II & $x$ & COMT & 0.177 & 0.1906 & 0.327 \\
\hline GA & $\times$ & BDNF & -0.018 & 0.8911 & 0.928 \\
\hline GA & $x$ & SLC6A4 & -0.059 & 0.6702 & 0.804 \\
\hline GA & $\times$ & COMT & -0.518 & 0.0001 & 0.001 \\
\hline Total brain vol & $\times$ & BDNF & 0.105 & 0.4362 & 0.654 \\
\hline Total brain vol & $\times$ & SLC6A4 & -0.043 & 0.7501 & 0.844 \\
\hline Total brain vol & $\times$ & COMT & 0.187 & 0.1532 & 0.283 \\
\hline
\end{tabular}

The direction of the loadings here depends on the reference allele for each genotype, e.g., for Surgery $\times$ BDNF genotype, the reference was the major allele $\mathrm{Nal}$ ) which was coded as 0 , therefore more surgeries with the presence of the minor allele indicates greater loading on the component PC NCFXG. Taken together Tables 4 and 6, smaller CA4DG volume was related to more surgeries in the presence of the BDNF minor allele. NCF variables: Infection, neonatal culture proven infection; Inv. Procedures, number of invasive procedures; Morphine, morphine exposure, Surgery, number of surgeries; Ventilation, days on mechanical ventilation, SNAP-II, Score for Neonatal Acute Physiology-Il on day 1 (i.e., illness severity on day 1); GA, gestational age. PC NCFxG, principal component of the interaction term between neonatal clinical factors and genotypes. ${ }^{a}$ Red font indicate $p<0.0045$ after Bonferroni adjustment for multiple comparisons. ${ }^{b}$ Red font indicate $p<0.05$ after Benjamini-Hochberg false discovery rate (FDR) 5\% overall error rate adjustment.

\section{CPCA Components Correlations With Cognitive, Motor and Behavioral Outcomes}

To examine whether alterations in subcortical brain volumes found in relation to neonatal clinical factors and genotypes in our sample of very preterm children were related to specific functional outcomes at 8 years, further analyses were conducted. CPCA component scores were extracted and correlated with WISC IV composite scores (VCI, PRI, WMI, and PSI), CBCL $T$-scores (Internalizing and Externalizing), BRIEF GEC scores, as well as the Beery VMI, Visual Perception and Motor coordination. Results are summarized in Table 7.

The WISC IV Perceptual Reasoning Index $(r=-0.27$, $p=0.042)$ and Beery Visual Perception scores $(r=-0.27$, 


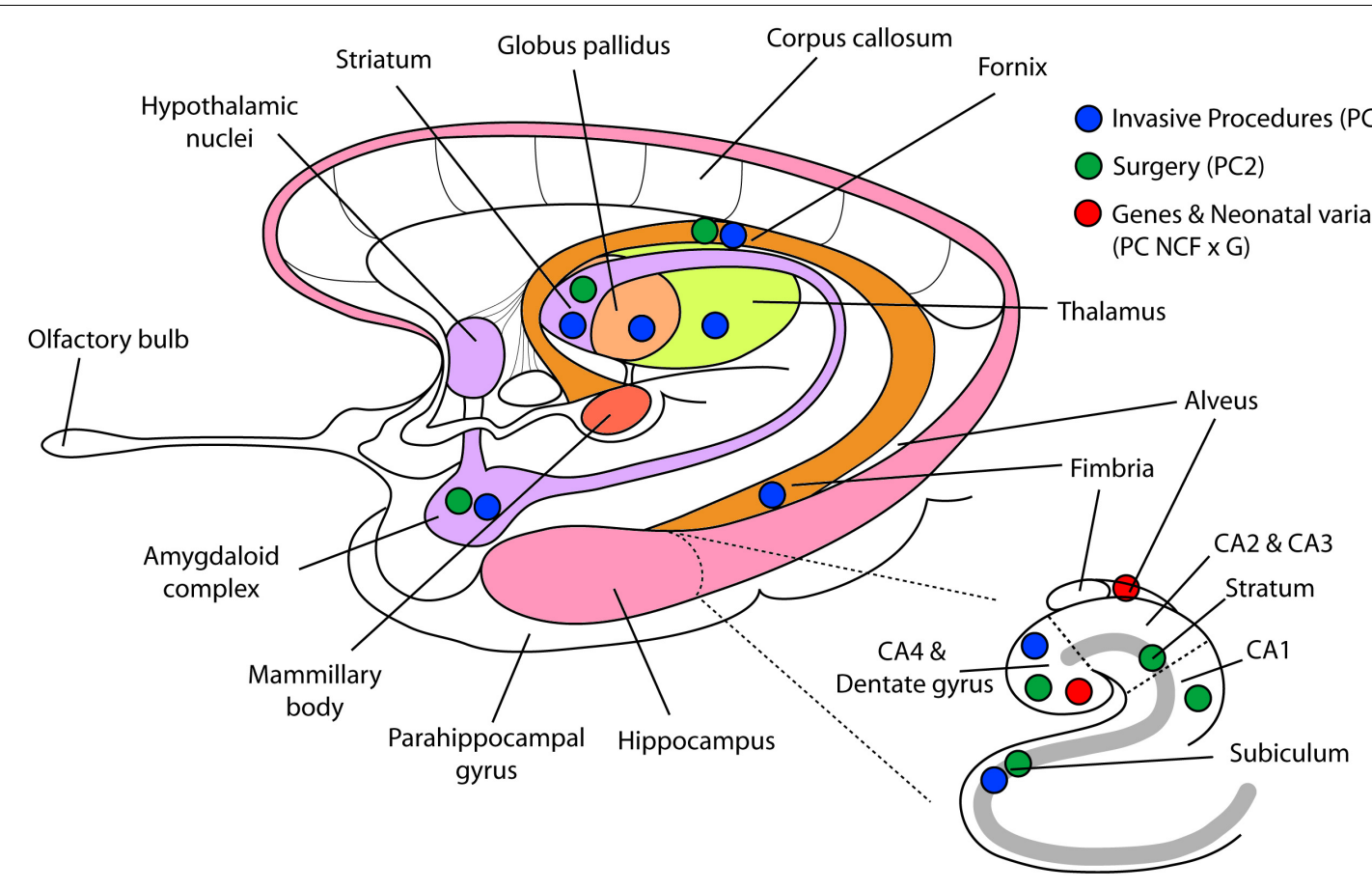

FIGURE 1 | Reduced regional volumes in limbic system, basal ganglia, and thalamus. This figure displays the results of the constrained principal component analysis. Blue dots representing number of invasive procedures (component 1) are displayed on the brain regions that were significantly altered. Green dots representing more surgeries (component 2) are displayed on brain regions that were bilaterally reduced by the number of neonatal surgeries. Red dots, representing the interaction term between neonatal clinical factors and genotypes, show the two brain regions significantly related to this interaction term. PC1, principal component 1; PC2, principal component 2; PC NCFxG, principal component of the interaction term between neonatal clinical factors and genotypes.

$p=0.047)$ negatively correlated with PC1, which was prominently loaded on the amygdala and thalamus (see Table 4), and mainly associated with neonatal invasive procedures (see Table 5). This suggested the possible vulnerability of amygdala and thalamus to neonatal invasive procedures, and poorer long-term outcomes on perceptual reasoning and visual perception. The WISC IV Verbal Comprehension Index $(r=-0.28, p=0.034)$ and the Beery Motor Coordination score $(r=-0.33, p=0.012)$ negatively correlated with PC2, which was prominently loaded on hippocampal subregions (see Table 4) and was associated with lower number of surgeries (see Table 5). Here, this surprising finding indicates a possible relationship between neonatal surgical procedures exposure and hippocampal-related structures, which in term alters executive functions at school age.

The interaction term (PC NCFxG) revealed to be the most strongly correlated with the neurobehavioral outcomes, indicating the interactions between genotypes (COMT, BDNF; see Table 6) and neonatal factors (infection, invasive procedures, surgery, GA; see Table 6), which were mainly loaded on CA4/DG and alveus. Here, this interaction term was associated with the WISC IV Working Memory $(r=-0.36, p=0.006)$ and Processing Speed scores $(r=-0.38, p=0.004)$, the CBCL externalizing behavior $T$-score $(r=-0.32, p=0.017)$, and the BRIEF GEC score $(r=-0.30, p=0.022)$. These findings indicate a potential vulnerability of the hippocampal structures and related tracks in very preterm children of a particular genotype, that were the sickest during their NICU admission (i.e., lower GA and higher exposure to invasive procedures, surgeries and infection).

\section{DISCUSSION}

This is the first study to integrate relationships among neonatal factors, subcortical brain structures and genetic moderators in relation to cognitive and behavioral outcomes at school age in children born very preterm. We found that greater exposure to neonatal pain/stress was associated with smaller regional volumes in the limbic system (hippocampal network, amygdala, and thalamus) and basal ganglia (striatum and globus pallidus) at age 8 years, after accounting for clinical factors associated with prematurity. COMT and BDNF genotypes moderated this relationship in both the hippocampal dentate gyrus and alveus. Moreover, smaller regional volumes in the limbic system and basal ganglia were associated with poorer cognitive performance and more behavioral problems, consistent with our hypotheses.

The hippocampal network consists of the hippocampal formation and its efferent pathways. The hippocampal formation is a subcortical structure, comprised of morphologically distinct but connected regions. After adjusting for total brain volume, our CPCA model indicated that among the seven neonatal clinical factors tested number of invasive procedures (indicator of neonatal pain exposure), days on mechanical ventilation 
TABLE 7 | Correlations between CPCA component scores and neurodevelopmental outcomes.

\begin{tabular}{|c|c|c|c|c|c|c|}
\hline & \multicolumn{2}{|c|}{ PC1 } & \multicolumn{2}{|c|}{ PC2 } & \multicolumn{2}{|c|}{ PC NCFxG } \\
\hline & $r$ & $p$-values & $r$ & $p$-values & $r$ & $p$-values \\
\hline $\begin{array}{l}\text { WISC-IV VCI } \\
\text { composite }\end{array}$ & -0.146 & 0.282 & -0.0284 & 0.034 & -0.147 & 0.280 \\
\hline $\begin{array}{l}\text { WISC-IV PRI } \\
\text { composite }\end{array}$ & -0.270 & 0.042 & -0.232 & 0.082 & -0.203 & 0.130 \\
\hline $\begin{array}{l}\text { WISC-IV WMI } \\
\text { composite }\end{array}$ & -0.142 & 0.298 & -0.244 & 0.070 & -0.363 & 0.006 \\
\hline $\begin{array}{l}\text { WISC-IV PSI } \\
\text { composite }\end{array}$ & -0.089 & 0.520 & -0.088 & 0.522 & -0.378 & 0.004 \\
\hline $\begin{array}{l}\text { CBCL internalizing } \\
\text { problems }\end{array}$ & -0.050 & 0.714 & -0.254 & 0.056 & 0.040 & 0.767 \\
\hline $\begin{array}{l}\text { CBCL externalizing } \\
\text { problems }\end{array}$ & -0.070 & 0.607 & -0.024 & 0.862 & 0.316 & 0.017 \\
\hline BRIEF GEC & 0.041 & 0.764 & 0.042 & 0.754 & 0.303 & 0.022 \\
\hline Beery VMI & -0.056 & 0.678 & -0.069 & 0.609 & -0.050 & 0.713 \\
\hline $\begin{array}{l}\text { Beery visual } \\
\text { perception }\end{array}$ & -0.265 & 0.047 & -0.250 & 0.061 & -0.152 & 0.258 \\
\hline $\begin{array}{l}\text { Beery motor } \\
\text { coordination }\end{array}$ & -0.121 & 0.370 & -0.332 & 0.012 & -0.229 & 0.087 \\
\hline
\end{tabular}

The direction of the correlation depends on the measure, e.g., WISC-IV and Beery scores higher is better, whereas CBCL and BRIEF problem scores lower is better. For example, higher PC1 was significantly correlated with poorer WISCIV Perceptual Reasoning and poorer Beery Visual Perception. Taking Tables 5 and 7 together, higher PC1 (more invasive procedures, more days on mechanical ventilation, lower GA, and smaller total brain volume) was related to poorer WISCIV Perceptual Reasoning and poorer Beery Visual Perception. PC1, principal component 1; PC2, principal component 2; PC NCFXG, principal component of the interaction term between neonatal clinical factors and genotypes; WISCIV, Wechsler Intelligence Scale for Children 4th Ed; VCl, Verbal Comprehension Index; PRI, Perceptual Reasoning Index; WMI, Working Memory; PSI, Processing Speed Index; CBCL, Child Behavior Checklist; BRIEF, Behavior Rating Inventory of Executive Function; GEC, Global Executive Composite. Significant p-values are in red font.

and gestational age were associated with smaller regional volumes bilaterally of CA4DG, fimbria, fornix, amygdala, striatum, globus pallidus, thalamus, and unilaterally with right subiculum. This finding seem to lead to alterations in long-term neurodevelopmental outcomes, as shown by poorer perceptual reasoning and visual perception at 8 years. Many of these regions have been previously reported to be involved in spatial orientation and memory (Wible et al., 1992; Jessberger et al., 2009; Hescham et al., 2017) and our results are consistent with these findings. Given our previous findings of altered cortical and subcortical gray and white matter structures in relation to exposure to pain and other clinical factors related to prematurity in very preterm children (Ranger et al., 2013; Vinall et al., 2013; Ranger et al., 2015), it is not surprising to find in the present study such a wide-spread detrimental effect of this early-stress exposure on regional volumes of the limbic system and basal ganglia. Interestingly, these affected subregions are mostly interconnected with the thalamus, the relayer of sensory and motor signals. Recently, in an independent cohort of very preterm infants, we found that neonatal procedural pain-related stress was associated with poorer thalamic growth from early life to term equivalent age, in turn related to poorer cognition and motor function at
3 years corrected age (Duerden et al., 2018). This relationship between pain/stress and slower thalamocortical growth was also reported in a Swiss cohort of very preterm infants (Schneider et al., 2018). Taken together, these studies indicate the importance of early-life stress in relation to thalamocortical development.

Thalamocortical connectivity is undergoing rapid development during the late second trimester of fetal life and is critical for how sensory information, including pain, is transmitted throughout the brain and then processed (Kostovic and Judas, 2010). Connections between subplate and cortices are at maximal at 24-28 weeks gestation and are particularly vulnerable to excitotoxicity (Kostovic and Judas, 2010; Verriotis et al., 2016). Even a single heel lance in preterm neonates or one incision in immature rodent pups can induce a cascade of physiological, hormonal, inflammatory, as well as evoked electrophysiological (EEG) responses and hemodynamic changes in the brain (Fitzgerald and Beggs, 2001; Bartocci et al., 2006; Slater et al., 2010; Fabrizi et al., 2011; Worley et al., 2012; Goksan et al., 2015; Hartley et al., 2017). Thus, given that very preterm infants undergo on average about 10 invasive procedures daily, it is conceivable that cumulative repeated exposure to invasive procedures could impact several important interconnected networks during this critical period of brain maturation. We have previously shown that neonatal exposure to pain-related stress was associated with long-term alterations in the spectral architecture of spontaneous brain oscillations, suggesting changes in thalamocortical connectivity (Doesburg et al., 2013). The associations between neonatal pain-related stress and smaller regional volumes in the major hippocampal output pathway (subiculum, fimbria, and fornix), basal ganglia (globus pallidus and striatum) and thalamus found in this study extend our previous findings, and confirm our recent reports of associations between neonatal procedural pain/stress and altered functional connectivity between thalamus and sensorimotor cortices in very preterm infants (Duerden et al., 2018; Schneider et al., 2018). Findings from our present study provide more detailed locations for potential effects of pain-related stress in subcortical brain structures.

Another major finding in this study was that the number of neonatal surgeries was associated with smaller volumes bilaterally in the CA1, CA4DG, hippocampal stratum, fornix, amygdala, striatum, and unilaterally in the right subiculum and CA2CA3 regions. Surprisingly, thalamic volume was not associated with surgery. However, it is difficult for us to speculate on the role that surgery plays in explaining the regional brain volumes since we cannot account for type of surgery (e.g., major versus minor) or duration, due to our limited sample size. We have previously reported that the number of neonatal surgeries (controlling for other neonatal confounders and concurrent maternal factors) predicted more anxiety/depressive symptoms at 8 years in very preterm children (Ranger et al., 2014). Further studies in larger cohorts of very preterm children are needed to examine in more detail the role of location and duration of surgery, as well as type and dosing of analgesic and sedative medications administered.

It is interesting that only the right subiculum region in the hippocampus was associated with neonatal invasive procedures and number of surgeries. The subiculum receives input signals 
from CA1 and outputs signals to the entorhinal and prefrontal cortices. The subiculum is situated at a pivotal junction between the hippocampus and the entorhinal cortex, and is thought to be involved in mnemonic processing and spatial navigation (O'Mara et al., 2001). Given the association between right hippocampus activity and mood disorder such as depression and anxiety (Malykhin et al., 2010; Mathias et al., 2016), and the finding of overall asymmetry in subiculum, further examination of this particular structure remains an interesting target for future studies.

To investigate possible pathways involved in the long-term neurodevelopmental outcomes of children born prematurely, we examined the interactions between neonatal clinical factors and genetic variants that are related to the availability of neurotransmitters dopamine (COMT) and serotonin (SLC6A4), and neurotrophin (BDNF), involved in neurogenesis. Interestingly, genotypes alone did not predict subcortical volumes in our sample of very preterm children at school age. Only interactions between genotypes and certain neonatal clinical factors were related to volume of the hippocampal cornu ammonis 4/dentate gyrus (CA4DG) and alveus. Surprisingly, this gene by environment effect was only found for the COMT and BDNF genotypes, but not SLC6A4. Specifically, smaller right hemisphere CA4DG and alveus were predicted by greater exposure to neonatal invasive procedure in very preterm children with COMT 158Met/Met, and by neonatal infection in those with the minor allele of BDNF Val66Met. Children with COMT $158 \mathrm{Met} / \mathrm{Met}$ genotype have been shown to have increased pain sensitivity (Zubieta et al., 2003; Diatchenko et al., 2005; Ahlers et al., 2013; Sadhasivam et al., 2014). An interactive effect on hippocampal volumes of early adversity and BDNF Met-carrier status has been described in major depressive disorder and psychosis (Aas et al., 2013; Carballedo et al., 2013). Moreover, hippocampus CA4DG has been shown to contribute to memory formation (e.g., Saxe et al., 2006; Jessberger et al., 2009; Thompson et al., 2014). The alveus, an important bundle of white matter fibers, contains axonal fibers from the DG and from pyramidal neurons of CA3, CA2, CA1 and subiculum to form the fimbria/fornix (reviewed by O'Mara et al., 2001). Early-life stress is associated with decreased neurogenesis and effects can persist throughout life, for example stress is one of the most potent inhibitors of neurogenesis in the hippocampus (Korosi et al., 2012). Hippocampal development is vulnerable to infection, hypoxia/ischemia, undernutrition, fetal intrauterine growth retardation as well as stress (Lodygensky et al., 2008; Sizonenko et al., 2008), all of which are complications that are associated with preterm birth. In the rodent pup, neonatal stress and/or noxious stimulation is associated with long-term alterations in hippocampal volumes (Malheiros et al., 2013; Victoria et al., 2013; Lima et al., 2014) and shortterm neurochemistry (Mooney-Leber et al., 2018). Consistent with the animal work, altered hippocampal morphology and reduced volumes have also been found in infants, children and adolescents born preterm compared to full-term peers (Nosarti et al., 2002; Thompson et al., 2008; Guo et al., 2015). Therefore, it appears that the hippocampus CA4DG region and the output pathway are particular sensitive to neonatal pain-related stress and infection exposure, which in turn contribute to the long-term cognitive and behavioral outcomes in children born very preterm (e.g., working memory, processing speed, and aggressive/rule-breaking behaviors).

Our findings that both postnatal infection and neonatal painrelated stress contributed to reduced volume in hippocampal subregions, suggests an important role of the immune system, given the close relationships between stress and immune function. The immune system plays a critical role in shaping the brain (reviewed by Bilbo and Schwarz, 2012), especially during the last fetal trimester and early postnatal life, which coincides with the timing of very preterm infant exposure to NICU care. In a neonatal rodent model, even a single invasive procedure induced immune responses, with effects evident until adulthood (Beggs et al., 2012). A growing body of evidence points to the early-life environment as central in shaping how the brain and immune system interact and develop, with significant consequences on behavioral outcomes across the lifespan (reviewed by Bilbo and Schwarz, 2009). Indeed, increasing our understanding of how an altered immune system may contribute to changes in brain and thereby later neurobehavioral outcomes, is an important area for future research in this population.

We recognize that this study has limitations, particularly the relatively limited sample size for examining interactions between neonatal clinical factors and genotypes. Unfortunately, due to the sample size, we could not examine sex differences. Nonetheless, unique to our study is the multi-modal approach of genotyping and neuroimaging in relation to neurobehavioral outcomes. Poorer cognitive function and behavior is still evident in adulthood in this vulnerable population (e.g., Grunau et al., 2004). Our work begins to unravel the complexity of pathways involved in outcomes of children born very preterm.

\section{CONCLUSION}

In a sample of very preterm children assessed at school age, neonatal clinical factors independently predicted a wide-spread of subregional volumes in the limbic system and basal ganglia, suggesting potential neurophysiological pathways between specific neonatal factors and subcortical structures. Neonatal exposure to invasive procedures, days on mechanical ventilation, and GA predicted smaller volumes in the CA4DG, fimbra, fornix, amygdala, striatum, globus pallidus, thalamus, and subiculum, which in turn were related to poorer perceptual reasoning and visual perception. Alongside, we showed that the number of surgeries during NICU admission predicted volumes of CA1, CA2CA3, CA4DG, hippocampal stratum, fornix, amygdala, striatum, and subiculum, which revealed to be associated with poorer verbal comprehension and motor coordination. Finally, through a gene by environment interaction analysis, we demonstrated that COMT genotype interacted with neonatal invasive procedures, while $B D N F$ genotype interacted with occurrence of neonatal infection to predict volume of CA4DG and alveus. This interaction was related to poorer working memory, processing speed, and executive functions, as well as 
more externalizing behaviors at 8 years in children born very preterm. Therefore, these important structures for emotional regulation, executive function and motor coordination appear to demonstrate differential vulnerability to early environmental adversity, which can be moderated by specific genotypes, and in turn are associated with altered child neurodevelopmental outcomes. These findings begin to address factors underlying the diversity of long-term outcomes in children born very preterm and the complexity that interplays when examining how exposure to early-life stress may impact brain development both at the structural and functional level.

\section{DATA AVAILABILITY}

The datasets for this manuscript are not publicly available because privacy issues. Requests to access the datasets should be directed to rgrunau@bcchr.ca.

\section{AUTHOR CONTRIBUTIONS}

REG conceived and designed the study. CC conducted the genotyping. KP was key to MRI acquisition and read all scans. MP

\section{REFERENCES}

Aas, M., Haukvik, U. K., Djurovic, S., Bergmann, O., Athanasiu, L., Tesli, M. S., et al. (2013). BDNF val66met modulates the association between childhood trauma, cognitive and brain abnormalities in psychoses. Prog. Neuropsychopharmacol. Biol. Psychiatry 46, 181-188. doi: 10.1016/j.pnpbp. 2013.07.008

Achenbach, T. M., and Rescorla, L. A. (2000). Manual for ASEBA Preschool Forms \& Profiles. Burlington, VT: University of Vermont.

Ahlers, S. J., Elens, L. L., van Gulik, L., van Schaik, R. H., van Dongen, E. P., Bruins, P., et al. (2013). The Val158Met polymorphism of the COMT gene is associated with increased pain sensitivity in morphine-treated patients undergoing a painful procedure after cardiac surgery. Br. J. Clin. Pharmacol. 75, 1506-1515. doi: 10.1111/bcp.12052

Amaral, R. S. C., Park, M. T. M., Devenyi, G. A., Lynn, V., Pipitone, J., Winterburn, J., et al. (2018). Manual segmentation of the fornix, fimbria, and alveus on high-resolution 3T MRI: application via fully-automated mapping of the human memory circuit white and grey matter in healthy and pathological aging. Neuroimage 170, 132-150. doi: 10.1016/j.neuroimage.2016. 10.027

Anderson, P., Doyle, L. W., and Victorian Infant Collaborative Study Group (2003). Neurobehavioral outcomes of school-age children born extremely low birth weight or very preterm in the 1990s. JAMA 289, 3264-3272. doi: 10.1001/jama. 289.24.3264

Ball, G., Pazderova, L., Chew, A., Tusor, N., Merchant, N., Arichi, T., et al. (2015). Thalamocortical connectivity predicts cognition in children born preterm. Cereb. Cortex 25, 4310-4318. doi: 10.1093/cercor/bhu331

Bartocci, M., Bergqvist, L. L., Lagercrantz, H., and Anand, K. J. (2006). Pain activates cortical areas in the preterm newborn brain. Pain 122, 109-117. doi: 10.1016/j.pain.2006.01.015

Beery, K. E., and Beery, M. A. (2004). The Beery-Buktenica Developmental-Test of Visual-Motor Integration, 5th Edn. Minneapolis, MN: NCS Pearson Inc.

Beggs, S., Currie, G., Salter, M. W., Fitzgerald, M., and Walker, S. M. (2012). Priming of adult pain responses by neonatal pain experience: maintenance by central neuroimmune activity. Brain 135(Pt 2), 404-417. doi: 10.1093/brain/ awr288 and RA performed MRI data processing and segmentation. CC conducted statistical analyses. CC, MR, RG, and SM interpreted the results. CC, MR, and RG drafted the manuscript. All authors edited and revised the manuscript and approved the final version of manuscript.

\section{FUNDING}

This study was supported by the Eunice Kennedy Shriver National Institute of Child Health and Human Development (NICHD) National Institutes of Health [R01 HD039783 (RG)], the Canadian Institutes of Health Research [CIHR MOP86489 (RG)], and BC Children's Hospital Research Institute Senior Scientist Award (RG).

\section{ACKNOWLEDGMENTS}

We thank the families and staff of the NICU at the BC Women's Hospital. We would like to thank Ivan Cepeda and Gisela Gosse for their invaluable work running this study, and Dr. Angela Devlin for providing equipment and support in her lab for genotyping.

Benjamini, Y., and Hochberg, Y. (1995). Controlling the false discovery rate: a practical and powerful approach to multiple testing. J. R. Stat. Soc. B 57, 289-300. doi: 10.2307/2346101

Bilbo, S. D., and Schwarz, J. M. (2009). Early-life programming of later-life brain and behavior: a critical role for the immune system. Front. Behav. Neurosci. 3:14. doi: 10.3389/neuro.08.014.2009

Bilbo, S. D., and Schwarz, J. M. (2012). The immune system and developmental programming of brain and behavior. Front. Neuroendocrinol. 33, 267-286. doi: 10.1016/j.yfrne.2012.08.006

Brummelte, S., Chau, C. M. Y., Cepeda, I. L., Degenhardt, A., Weinberg, J., Synnes, A. R., et al. (2015). Cortisol levels in former preterm children at school age are predicted by neonatal procedural pain-related stress. Psychoneuroendocrinology 51, 151-163. doi: 10.1016/j.psyneuen.2014.09.018

Brummelte, S., Grunau, R. E., Chau, V., Poskitt, K. J., Brant, R., Vinall, J., et al. (2012). Procedural pain and brain development in premature newborns. Ann. Neurol. 71, 385-396. doi: 10.1002/ana.22267

Brunnemann, N., Kipp, K. H., Gortner, L., Meng-Hentschel, J., Papanagiotou, P., Reith, W., et al. (2013). Alterations in the relationship between hippocampal volume and episodic memory performance in preterm children. Dev. Neuropsychol. 38, 226-235. doi: 10.1080/87565641.2013.773003

Carbajal, R., Rousset, A., Danan, C., Coquery, S., Nolent, P., Ducrocq, S., et al. (2008). Epidemiology and treatment of painful procedures in neonates in intensive care units. JAMA 300, 60-70. doi: 10.1001/jama.300.1.60

Carballedo, A., Morris, D., Zill, P., Fahey, C., Reinhold, E., Meisenzahl, E., et al. (2013). Brain-derived neurotrophic factor Val66Met polymorphism and early life adversity affect hippocampal volume. Am. J. Med. Genet. B Neuropsychiatr. Genet. 162B, 183-190. doi: 10.1002/ajmg.b.32130

Chakravarty, M. M., Steadman, P., van Eede, M. C., Calcott, R. D., Gu, V., Shaw, P., et al. (2013). Performing label-fusion-based segmentation using multiple automatically generated templates. Hum. Brain Mapp. 34, 2635-2654. doi: 10.1002/hbm.22092

Chau, C. M., Cepeda, I. L., Devlin, A. M., Weinberg, J., and Grunau, R. E. (2017). The Val66Met brain-derived neurotrophic factor gene variant interacts with early pain exposure to predict cortisol dysregulation in 7-year-old children born very preterm: implications for cognition. Neuroscience 342, 188-199. doi: 10.1016/j.neuroscience.2015.08.044 
Chau, C. M. Y., Ranger, M., Sulistyoningrum, D., Devlin, A. M., Oberlander, T. F., and Grunau, R. E. (2014). Neonatal pain and COMT Val158Met genotype in relation to serotonin transporter (SLC6A4) promoter methylation in very preterm children at school age. Front. Behav. Neurosci. 8:409. doi: 10.3389/ fnbeh.2014.00409

Chen, B., Dowlatshahi, D., MacQueen, G. M., Wang, J. F., and Young, L. T. (2001). Increased hippocampal BDNF immunoreactivity in subjects treated with antidepressant medication. Biol. Psychiatry 50, 260-265. doi: 10.1016/ S0006-3223(01)01083-6

Chen, J., Lipska, B. K., Halim, N., Ma, Q. D., Matsumoto, M., Melhem, S., et al. (2004). Functional analysis of genetic variation in catechol-O-methyltransferase (COMT): effects on mRNA, protein, and enzyme activity in postmortem human brain. Am. J. Hum. Genet. 75, 807-821. doi: 10.1086/425589

Diatchenko, L., Slade, G. D., Nackley, A. G., Bhalang, K., Sigurdsson, A., Belfer, I., et al. (2005). Genetic basis for individual variations in pain perception and the development of a chronic pain condition. Hum. Mol. Genet. 14, 135-143. doi: 10.1093/hmg/ddi013

Doesburg, S. M., Chau, C. M., Cheung, T. P., Moiseev, A., Ribary, U., Herdman, A. T., et al. (2013). Neonatal pain-related stress, functional cortical activity and visual-perceptual abilities in school-age children born at extremely low gestational age. Pain 154, 1946-1952. doi: 10.1016/j.pain.2013. 04.009

Doyle, L. W., and Anderson, P. J. (2010). Adult outcome of extremely preterm infants. Pediatrics 126, 342-351. doi: 10.1542/peds.2010-0710

Duerden, E. G., Grunau, R. E., Guo, T., Foong, J., Pearson, A., Au-Young, S., et al. (2018). Early procedural pain is associated with regionally-specific alterations in thalamic development in preterm neonates. J. Neurosci. 38, 878-886. doi: 10.1523/JNEUROSCI.0867-17.2017

Duerden, E. G., Guo, T., Dodbiba, L., Chakravarty, M. M., Chau, V., Poskitt, K. J., et al. (2016). Midazolam dose correlates with abnormal hippocampal growth and neurodevelopmental outcome in preterm infants. Ann. Neurol. 79, 548-559. doi: 10.1002/ana.24601

Egan, M. F., Goldberg, T. E., Kolachana, B. S., Callicott, J. H., Mazzanti, C. M., Straub, R. E., et al. (2001). Effect of COMT Val108/158 met genotype on frontal lobe function and risk for schizophrenia. Proc. Natl. Acad. Sci. U.S.A. 98, 6917-6922. doi: 10.1073/pnas.111134598

Egan, M. F., Kojima, M., Callicott, J. H., Goldberg, T. E., Kolachana, B. S., Bertolino, A., et al. (2003). The BDNF val66met polymorphism affects activitydependent secretion of BDNF and human memory and hippocampal function. Cell 112, 257-269. doi: 10.1016/S0092-8674(03)00035-7

Fabrizi, L., Slater, R., Worley, A., Meek, J., Boyd, S., Olhede, S., et al. (2011). A shift in sensory processing that enables the developing human brain to discriminate touch from pain. Curr. Biol. 21, 1552-1558. doi: 10.1016/j.cub.2011.08.010

Fitzgerald, M., and Beggs, S. (2001). The neurobiology of pain: developmental aspects. Neuroscientist 7, 246-257. doi: 10.1177/107385840100700309

Gerritsen, L., Tendolkar, I., Franke, B., Vasquez, A. A., Kooijman, S., Buitelaar, J., et al. (2012). BDNF Val66Met genotype modulates the effect of childhood adversity on subgenual anterior cingulate cortex volume in healthy subjects. Mol. Psychiatry 17, 597-603. doi: 10.1038/mp.2011.51

Gioia, G. A., Isquith, P. K., Guy, S. C., and Kenworthy, L. (2000). Behavior rating inventory of executive function. Child Neuropsychol. 6, 235-238. doi: 10.1076/ chin.6.3.235.3152

Goksan, S., Hartley, C., Emery, F., Cockrill, N., Poorun, R., Moultrie, F., et al. (2015). fMRI reveals neural activity overlap between adult and infant pain. eLife 4:e06356. doi: 10.7554/eLife.06356

Govindarajan, A., Rao, B. S., Nair, D., Trinh, M., Mawjee, N., Tonegawa, S., et al. (2006). Transgenic brain-derived neurotrophic factor expression causes both anxiogenic and antidepressant effects. Proc. Natl. Acad. Sci. U.S.A. 103, 13208-13213. doi: 10.1073/pnas.0605180103

Grunau, R. E., Cepeda, I. L., Chau, C. M. Y., Brummelte, S., Weinberg, J., Lavoie, P., et al. (2013). Neonatal pain-related stress and NFKBIA genotype are associated with altered cortisol levels in preterm boys at school age. PLoS One 8:e73926. doi: 10.1371/journal.pone.0073926

Grunau, R. E., Haley, D. W., Whitfield, M. F., Weinberg, J., Yu, W., and Thiessen, P. (2007). Altered basal cortisol levels at 3, 6, 8 and 18 months in infants born at extremely low gestational age. J. Pediatr. 150, 151-156. doi: 10.1016/j.jpeds. 2006.10.053
Grunau, R. E., Holsti, L., Haley, D. W., Oberlander, T., Weinberg, J., Solimano, A., et al. (2005). Neonatal procedural pain exposure predicts lower cortisol and behavioral reactivity in preterm infants in the NICU. Pain 113, 293-300. doi: 10.1016/j.pain.2004.10.020

Grunau, R. E., Whitfield, M. F., and Fay, T. B. (2004). Psychosocial and academic characteristics of extremely low birth weight $(<$ or $=800 \mathrm{~g}$ ) adolescents who are free of major impairment compared with term-born control subjects. Pediatrics 114, e725-e732. doi: 10.1542/peds.2004-0932

Grunau, R. E., Whitfield, M. F., Petrie-Thomas, J., Synnes, A. R., Cepeda, I. L., Keidar, A., et al. (2009). Neonatal pain, parenting stress and interaction, in relation to cognitive and motor development at 8 and 18 months in preterm infants. Pain 143, 138-146. doi: 10.1016/j.pain.2009.02.014

Guo, T., Winterburn, J. L., Pipitone, J., Duerden, E. G., Park, M. T., Chau, V., et al. (2015). Automatic segmentation of the hippocampus for preterm neonates from early-in-life to term-equivalent age. Neuroimage Clin. 9, 176-193. doi: 10.1016/j.nicl.2015.07.019

Hartley, C., Duff, E. P., Green, G., Mellado, G. S., Worley, A., Rogers, R., et al. (2017). Nociceptive brain activity as a measure of analgesic efficacy in infants. Sci. Transl. Med. 9:eaah6122. doi: 10.1126/scitranslmed. aah6122

Hescham, S., Temel, Y., Schipper, S., Lagiere, M., Schonfeld, L. M., Blokland, A., et al. (2017). Fornix deep brain stimulation induced long-term spatial memory independent of hippocampal neurogenesis. Brain Struct. Funct. 222, 1069-1075. doi: 10.1007/s00429-016-1188-y

Hoth, K. F., Paul, R. H., Williams, L. M., Dobson-Stone, C., Todd, E., Schofield, P. R., et al. (2006). Associations between the COMT Val/Met polymorphism, early life stress, and personality among healthy adults. Neuropsychiatr. Dis. Treat. 2, 219-225. doi: 10.2147/nedt.2006.2.2.219

Jessberger, S., Clark, R. E., Broadbent, N. J., Clemenson, G. D. Jr., Consiglio, A., Lie, D. C., et al. (2009). Dentate gyrus-specific knockdown of adult neurogenesis impairs spatial and object recognition memory in adult rats. Learn. Mem. 16, 147-154. doi: 10.1101/lm.1172609

Johnston, C., Barrington, K. J., Taddio, A., Carbajal, R., and Filion, F. (2011). Pain in canadian NICUs: have we improved over the past 12 years? Clin. J. Pain 27, 225-232. doi: 10.1097/AJP.0b013e3181fe14cf

Kim, S. N., Kang, D. H., Yun, J. Y., Lee, T. Y., Jung, W. H., Jang, J. H., et al. (2013). Impact of the BDNF Val66Met polymorphism on regional brain gray matter volumes: relevance to the stress response. Psychiatry Invest. 10, 173-179. doi: $10.4306 /$ pi.2013.10.2.173

Kinney, H. C. (2009). The encephalopathy of prematurity: one pediatric neuropathologist's perspective. Semin. Pediatr. Neurol. 16, 179-190. doi: 10. 1016/j.spen.2009.09.003

Korosi, A., Naninck, E. F., Oomen, C. A., Schouten, M., Krugers, H., Fitzsimons, C., et al. (2012). Early-life stress mediated modulation of adult neurogenesis and behavior. Behav. Brain Res. 227, 400-409. doi: 10.1016/j.bbr.2011.07.037

Kostovic, I., and Judas, M. (2010). The development of the subplate and thalamocortical connections in the human foetal brain. Acta Paediatr. 99, 1119-1127. doi: 10.1111/j.1651-2227.2010.01811.x

Lakshminarasimhan, H., and Chattarji, S. (2012). Stress leads to contrasting effects on the levels of brain derived neurotrophic factor in the hippocampus and amygdala. PLoS One 7:e30481. doi: 10.1371/journal.pone.0030481

Lesch, K. P. (2007). Linking emotion to the social brain. The role of the serotonin transporter in human social behaviour. EMBO Rep. 8(Suppl. 1), S24-S29. doi: 10.1038/sj.embor.7401008

Lesch, K. P., Bengel, D., Heils, A., Sabol, S. Z., Greenberg, B. D., Petri, S., et al. (1996). Association of anxiety-related traits with a polymorphism in the transporter gene regulatory region. Science 274, 1527-1531. doi: 10.1126/ science.274.5292.1527

Lima, M., Malheiros, J., Negrigo, A., Tescarollo, F., Medeiros, M., Suchecki, D., et al. (2014). Sex-related long-term behavioral and hippocampal cellular alterations after nociceptive stimulation throughout postnatal development in rats. Neuropharmacology 77, 268-276. doi: 10.1016/j.neuropharm.2013. 10.007

Linsell, L., Johnson, S., Wolke, D., O’Reilly, H., Morris, J. K., Kurinczuk, J. J., et al. (2018). Cognitive trajectories from infancy to early adulthood following birth before 26 weeks of gestation: a prospective, population-based cohort study. Arch. Dis. Child. 103, 363-370. doi: 10.1136/archdischild-2017-313414 
Lodygensky, G. A., Seghier, M. L., Warfield, S. K., Tolsa, C. B., Sizonenko, S., Lazeyras, F., et al. (2008). Intrauterine growth restriction affects the preterm infant's hippocampus. Pediatr. Res. 63, 438-443. doi: 10.1203/PDR. 0b013e318165c005

Lotta, T., Vidgren, J., Tilgmann, C., Ulmanen, I., Melen, K., Julkunen, I., et al. (1995). Kinetics of human soluble and membrane-bound catechol O-methyltransferase: a revised mechanism and description of the thermolabile variant of the enzyme. Biochemistry 34, 4202-4210. doi: 10.1021/bi00013a008

Lucki, I. (1998). The spectrum of behaviors influenced by serotonin. Biol. Psychiatry 44, 151-162. doi: 10.1016/S0006-3223(98)00139-5

Malheiros, J. M., Lima, M., Avanzi, R. D., Gomes da Silva, S., Suchecki, D., Guinsburg, R., et al. (2013). Repetitive noxious neonatal stimuli increases dentate gyrus cell proliferation and hippocampal brain-derived neurotrophic factor levels. Hippocampus 24, 415-423. doi: 10.1002/hipo.22235

Malykhin, N. V., Carter, R., Seres, P., and Coupland, N. J. (2010). Structural changes in the hippocampus in major depressive disorder: contributions of disease and treatment. J. Psychiatry Neurosci. 35, 337-343. doi: 10.1503/jpn. 100002

Mathias, S. R., Knowles, E. E., Kent, J. W. Jr., McKay, D. R., Curran, J. E., de Almeida, M. A., et al. (2016). Recurrent major depression and right hippocampal volume: a bivariate linkage and association study. Hum. Brain Mapp. 37, 191-202. doi: 10.1002/hbm.23025

Mooney-Leber, S. M., Spielmann, S. S., and Brummelte, S. (2018). Repetitive neonatal pain and reduced maternal care alter brain neurochemistry. Dev. Psychobiol. 60, 963-974. doi: 10.1002/dev.21777

Nackley, A. G., Shabalina, S. A., Tchivileva, I. E., Satterfield, K., Korchynskyi, O., Makarov, S. S., et al. (2006). Human catechol-O-methyltransferase haplotypes modulate protein expression by altering mRNA secondary structure. Science 314, 1930-1933. doi: 10.1126/science.1131262

Nosarti, C., Al-Asady, M. H., Frangou, S., Stewart, A. L., Rifkin, L., and Murray, R. M. (2002). Adolescents who were born very preterm have decreased brain volumes. Brain 125(Pt 7), 1616-1623. doi: 10.1093/brain/awf157

Olsson, C. A., Byrnes, G. B., Anney, R. J., Collins, V., Hemphill, S. A., Williamson, R., et al. (2007). COMT val(158)met and 5HTTLPR functional loci interact to predict persistence of anxiety across adolescence: results from the victorian adolescent health cohort study. Genes Brain Behav. 6, 647-652. doi: 10.1111/j.1601-183X.2007.00313.x

O'Mara, S. M., Commins, S., Anderson, M., and Gigg, J. (2001). The subiculum: a review of form, physiology and function. Prog. Neurobiol. 64, 129-155. doi: 10.1016/S0301-0082(00)00054-X

Peterson, B. S., Vohr, B., Staib, L. H., Cannistraci, C. J., Dolberg, A., Schneider, K. C., et al. (2000). Regional brain volume abnormalities and long-term cognitive outcome in preterm infants. JAMA 284, 1939-1947. doi: 10.1001/ jama.284.15.1939

Pezawas, L., Meyer-Lindenberg, A., Drabant, E. M., Verchinski, B. A., Munoz, K. E., Kolachana, B. S., et al. (2005). 5-HTTLPR polymorphism impacts human cingulate-amygdala interactions: a genetic susceptibility mechanism for depression. Nat. Neurosci. 8, 828-834. doi: 10.1038/nn1463

Pipitone, J., Park, M. T., Winterburn, J., Lett, T. A., Lerch, J. P., Pruessner, J. C., et al. (2014). Multi-atlas segmentation of the whole hippocampus and subfields using multiple automatically generated templates. Neuroimage 101, 494-512. doi: 10.1016/j.neuroimage.2014.04.054

Provenzi, L., Fumagalli, M., Sirgiovanni, I., Giorda, R., Pozzoli, U., Morandi, F., et al. (2015). Pain-related stress during the neonatal intensive care unit stay and SLC6A4 methylation in very preterm infants. Front. Behav. Neurosci. 9:99. doi: 10.3389/fnbeh.2015.00099

Ranger, M., Chau, C. M., Garg, A., Woodward, T. S., Beg, M. F., Bjornson, B., et al. (2013). Neonatal pain-related stress predicts cortical thickness at age 7 years in children born very preterm. PLoS One 8:e76702. doi: 10.1371/journal.pone. 0076702

Ranger, M., Synnes, A. R., Vinall, J., and Grunau, R. E. (2014). Internalizing behaviours in school-age children born very preterm are predicted by neonatal pain and morphine exposure. Eur. J. Pain 18, 844-852. doi: 10.1002/j.15322149.2013.00431.x

Ranger, M., Zwicker, J. G., Chau, C. M., Park, M. T., Chakravarthy, M. M., Poskitt, K., et al. (2015). Neonatal pain and infection relate to smaller cerebellum in very preterm children at school age. J. Pediatr. 167, 292.e1-298.e1. doi: $10.1016 /$ j.jpeds.2015.04.055
Rasmusson, A. M., Shi, L., and Duman, R. (2002). Downregulation of BDNF mRNA in the hippocampal dentate gyrus after re-exposure to cues previously associated with footshock. Neuropsychopharmacology 27, 133-142. doi: 10. 1016/S0893-133X(02)00286-5

Richardson, D. K., Corcoran, J. D., Escobar, G. J., and Lee, S. K. (2001). SNAP-II and SNAPPE-II: simplified newborn illness severity and mortality risk scores. J. Pediatr. 138, 92-100. doi: 10.1067/mpd.2001.109608

Rogers, C. E., Sylvester, C. M., Mintz, C., Kenley, J. K., Shimony, J. S., Barch, D. M., et al. (2017). Neonatal amygdala functional connectivity at rest in healthy and preterm infants and early internalizing symptoms. J. Am. Acad. Child Adolesc. Psychiatry 56, 157-166. doi: 10.1016/j.jaac.2016. 11.005

Roofthooft, D. W., Simons, S. H., Anand, K. J., Tibboel, D., and van Dijk, M. (2014). Eight years later, are we still hurting newborn infants? Neonatology 105, 218-226. doi: 10.1159/000357207

Sadhasivam, S., Chidambaran, V., Olbrecht, V. A., Esslinger, H. R., Zhang, K., Zhang, X., et al. (2014). Genetics of pain perception, COMT and postoperative pain management in children. Pharmacogenomics 15, 277-284. doi: 10.2217/ pgs. 13.248

Saxe, M. D., Battaglia, F., Wang, J. W., Malleret, G., David, D. J., Monckton, J. E., et al. (2006). Ablation of hippocampal neurogenesis impairs contextual fear conditioning and synaptic plasticity in the dentate gyrus. Proc. Natl. Acad. Sci. U.S.A. 103, 17501-17506. doi: 10.1073/pnas.0607 207103

Scheinost, D., Kwon, S. H., Lacadie, C., Sze, G., Sinha, R., Constable, R. T., et al. (2016). Prenatal stress alters amygdala functional connectivity in preterm neonates. Neuroimage. Clin. 12, 381-388. doi: 10.1016/j.nicl.2016. 08.010

Schneider, J., Duerden, E. G., Guo, T., Ng, K., Hagmann, P., Bickle Graz, M., et al. (2018). Procedural pain and oral glucose in preterm neonates: brain development and sex-specific effects. Pain 159, 515-525. doi: 10.1097/j.pain. 0000000000001123

Simons, S. H., van Dijk, M., Anand, K. S., Roofthooft, D., van Lingen, R. A., and Tibboel, D. (2003). Do we still hurt newborn babies? A prospective study of procedural pain and analgesia in neonates. Arch. Pediatr. Adolesc. Med. 157, 1058-1064. doi: 10.1001/archpedi.157.11.1058

Sizonenko, S. V., Borradori-Tolsa, C., and Huppi, P. S. (2008). Intrauterine growth restriction: impact on brain development and function. Rev. Med. Suisse 4, 509-510.

Slater, R., Worley, A., Fabrizi, L., Roberts, S., Meek, J., Boyd, S., et al. (2010). Evoked potentials generated by noxious stimulation in the human infant brain. Eur. J. Pain 14, 321-326. doi: 10.1016/j.ejpain.2009.05.005

Tam, E. W., Chau, V., Ferriero, D. M., Barkovich, A. J., Poskitt, K. J., Studholme, C., et al. (2011). Preterm cerebellar growth impairment after postnatal exposure to glucocorticoids. Sci. Transl. Med. 3:105ra105. doi: 10.1126/scitranslmed. 3002884

Thompson, D. K., Omizzolo, C., Adamson, C., Lee, K. J., Stargatt, R., Egan, G. F., et al. (2014). Longitudinal growth and morphology of the hippocampus through childhood: impact of prematurity and implications for memory and learning. Hum. Brain Mapp. 35, 4129-4139. doi: 10.1002/hbm.22464

Thompson, D. K., Wood, S. J., Doyle, L. W., Warfield, S. K., Lodygensky, G. A., Anderson, P. J., et al. (2008). Neonate hippocampal volumes: prematurity, perinatal predictors, and 2-year outcome. Ann. Neurol. 63, 642-651. doi: 10. 1002/ana.21367

Verriotis, M., Chang, P., Fitzgerald, M., and Fabrizi, L. (2016). The development of the nociceptive brain. Neuroscience 338, 207-219. doi: 10.1016/j.neuroscience. 2016.07.026

Victoria, N. C., Inoue, K., Young, L. J., and Murphy, A. Z. (2013). A single neonatal injury induces life-long deficits in response to stress. Dev. Neurosci. 35, 326-337. doi: $10.1159 / 000351121$

Vinall, J., Grunau, R. E., Brant, R., Chau, V., Poskitt, K. J., Synnes, A. R., et al. (2013). Slower postnatal growth is associated with delayed cerebral cortical maturation in preterm newborns. Sci. Transl. Med. 5:168ra8. doi: 10.1126/ scitranslmed.3004666

Vinall, J., Miller, S., Bjornson, B., Fitzpatrick, K., Poskitt, K., Brant, R., et al. (2014). Invasive procedures in preterm children: brain and cognitive development at school age. Pediatrics 133, 412-421. doi: 10.1542/peds. 2013-1863 
Wechsler, D. (2003). Wechsler Intelligence Scales for Children, 4th Edn. San Antonio, TX: Psychological Corporation.

Wible, C. G., Shiber, J. R., and Olton, D. S. (1992). Hippocampus, fimbria-fornix, amygdala, and memory: object discriminations in rats. Behav. Neurosci. 106, 751-761. doi: 10.1037/0735-7044.106.5.751

Winterburn, J. L., Pruessner, J. C., Chavez, S., Schira, M. M., Lobaugh, N. J., Voineskos, A. N., et al. (2013). A novel in vivo atlas of human hippocampal subfields using high-resolution $3 \mathrm{~T}$ magnetic resonance imaging. Neuroimage 74, 254-265. doi: 10.1016/j.neuroimage.2013.02.003

Worley, A., Fabrizi, L., Boyd, S., and Slater, R. (2012). Multi-modal pain measurements in infants. J. Neurosci. Methods 205, 252-257. doi: 10.1016/j. jneumeth.2012.01.009

Zubieta, J. K., Heitzeg, M. M., Smith, Y. R., Bueller, J. A., Xu, K., Xu, Y., et al. (2003). COMT val158met genotype affects mu-opioid neurotransmitter responses to a pain stressor. Science 299, 1240-1243. doi: 10.1126/science. 1078546
Zwicker, J. G., Grunau, R. E., Adams, E., Chau, V., Brant, R., Poskitt, K. J., et al. (2013). Score for neonatal acute physiology-II and neonatal pain predict corticospinal tract development in premature newborns. Pediatr. Neurol. 48, 123.e1-129.e1. doi: 10.1016/j.pediatrneurol.2012.10.016

Conflict of Interest Statement: The authors declare that the research was conducted in the absence of any commercial or financial relationships that could be construed as a potential conflict of interest.

Copyright () 2019 Chau, Ranger, Bichin, Park, Amaral, Chakravarty, Poskitt, Synnes, Miller and Grunau. This is an open-access article distributed under the terms of the Creative Commons Attribution License (CC BY). The use, distribution or reproduction in other forums is permitted, provided the original author(s) and the copyright owner(s) are credited and that the original publication in this journal is cited, in accordance with accepted academic practice. No use, distribution or reproduction is permitted which does not comply with these terms. 